\title{
Níveis de irrigação na cultura do feijão caupi
}

\author{
Aderson S. de Andrade Júnior ${ }^{1}$, Braz H. N. Rodrigues², José A. Frizzone ${ }^{3}$, Milton J. Cardoso ${ }^{4}$, \\ Edson A. Bastos ${ }^{5} \&$ Francisco de B. Melo ${ }^{6}$

\begin{abstract}
1 Embrapa Meio Norte. CP 01, CEP 64006-220, Teresina, PI. Fone: (86) 225-1141. E-mail: aderson@cpamn.embrapa.br (Foto) 2 Embrapa Meio Norte/UEP de Parnaíba. CP 341, CEP 64200-970, Parnaíba, PI. Fone: (86) 315-1200. E-mail: braz@cpamn.embrapa.br 3 DER/ESALQ/USP. CP 09, CEP 13418-970, Piracicaba, SP. Fone: (19) 429-4217. E-mail: frizzone@cpamn.embrapa.br

4 Embrapa Meio Norte. Fone: (86) 225-1141. E-mail: milton@cpamn.embrapa.br

${ }^{5}$ Embrapa Meio Norte/UEP. Fone: (86) 215-1200. E-mail: edson@cpamn.embrapa.br

${ }^{6}$ Embrapa Meio Norte. Fone: (86) 225.1141. E-mail: brito@cpamn.embrapa.br
\end{abstract}

Protocolo 029 - 20/3/2001

\begin{abstract}
Resumo: Conduziu-se este trabalho com o objetivo de se avaliar os efeitos da aplicação de lâminas de irrigação sobre a produção de grãos e seus componentes em cultivares de feijão caupi (Vigna unguiculata L. Walp) nas condições edafoclimáticas dos Tabuleiros Costeiros do Piauí. $\mathrm{O}$ ensaio foi executado na área experimental da Embrapa Meio-Norte, em Parnaíba, PI, em Neossolo Quartzarênico Órtico Típico, durante o período de agosto a outubro de 1998. As lâminas de irrigação foram aplicadas através de um sistema de irrigação por "aspersão em linha". Os tratamentos consistiram na combinação de quatro lâminas de irrigação $(449,1 ; 428,6 ; 317,1$ e 194,4 mm) e duas cultivares de caupi (BR 17 Gurguéia e BR 14 Mulato) dispostos em um delineamento experimental de blocos casualizados, com parcelas subdivididas e cinco repetições. Houve efeito significativo $(p<0,05)$ da interação cultivar versus lâmina de irrigação somente para o número de vagens por planta (NVP) e para a produtividade de grãos (PG). A análise de regressão revelou que o maior $\operatorname{NVP}(25,6)$ e a máxima $\operatorname{PG}\left(2.809 \mathrm{~kg} \mathrm{ha}^{-1}\right)$, para a cultivar BR 17 Gurguéia, foram obtidos com a lâmina de irrigação correspondente a 449,1 mm. Para a cultivar BR 14 Mulato, os valores máximos de NVP $(15,0)$ e PG $\left(2.103,4 \mathrm{~kg} \mathrm{ha}^{-1}\right)$ foram obtidos com as lâminas de irrigação relativas a 363,5 e 389,9 mm, respectivamente.
\end{abstract}

Palavras-chave: Vigna unguiculata, feijão-de-corda, manejo da irrigação

\section{Irrigation levels and cowpea crop}

\begin{abstract}
This work was carried out to evaluate the effect of irrigation depth on yield and production components of cowpea (Vigna unguiculata L. Walp) under soil and climatic conditions of the Coastal Tablelands in the State of Piauí - Brazil. The trial was conducted at the Embrapa Meio-Norte Experimental Area, in Parnaíba, in a sandy soil, during the period from August to October, 1998. Irrigation depths were applied through a sprinkler line source system. The treatments were constituted by combination of four depths of irrigation $(449.1 ; 428.6 ; 317.1$ and $194.4 \mathrm{~mm}$ ) and two cowpea cultivars (BR 17 Gurguéia and BR 14 Mulato) arranged in a completely randomized block design in split-plot and five replications. Significant effects $(p<0.05)$ of depth of irrigation and cultivar interaction with respect to number of pods per plant (NPP) and grain yield (GY) were observed. The highest NPP (25.6) and maximum GY $\left(2,809 \mathrm{~kg} \mathrm{ha}^{-1}\right)$ for the BR 17 Gurguéia cultivar was obtained with the irrigation depth of $449.1 \mathrm{~mm}$. The maximum NPP (15.0) and GY $\left(2,103.4 \mathrm{~kg} \mathrm{ha}^{-1}\right)$ for the BR 14 Mulato cultivar were obtained with the irrigation depth of 363.5 and $389.9 \mathrm{~mm}$, respectively.
\end{abstract}

Key words: Vigna unguiculata, cowpea, irrigation management

\section{INTRODUÇÃO}

O feijão caupi (Vigna unguiculata (L.) Walp.) é uma cultura importante para as populações das regiões Norte e Nordeste do Brasil, principalmente por se constituir na principal fonte protéica de origem vegetal. É amplamente cultivado pelos pequenos agricultores verificando-se, ultimamente, uma expansão de área com a cultura em cultivos comerciais sob condição de irrigação (Cardoso et al., 1991); no entanto, os níveis de produtividade alcançados em regime irrigado $\left(1.200 \mathrm{~kg} \mathrm{ha}^{-1}\right)$, estão aquém dos que poderiam ser realmente obtidos com um manejo de irrigação adequado, durante as fases vegetativa e reprodutiva, buscando-se maximizar a eficiência do uso de água pela cultura. 
Diversos estudos têm sido realizados com o intuito de se viabilizar, técnica e economicamente, o cultivo, em regime irrigado, da cultura do feijão (Felipe et al., 1992; Carvalho et al., 1992; Azevedo \& Miranda, 1996; entre outros); entretanto, os resultados obtidos foram bastante distintos e não conclusivos quanto à definição da melhor lâmina de irrigação para a cultura; além disso, na sua grande maioria, esses estudos foram realizados utilizando-se cultivares da espécie Phaseolus vulgaris, os quais não podem ser indistintamente extrapolados para cultivares da espécie Vigna unguiculata. Em estudos dessa natureza, os resultados são bastante influenciados pelas cultivares utilizadas e pelas condições edafoclimáticas da região.

Com este trabalho, objetivou-se avaliar os efeitos da aplicação de quatro lâminas de irrigação sobre a produção de grãos e seus componentes, em duas cultivares de feijão caupi, nas condições edafoclimáticas dos Tabuleiros Costeiros do Piauí.

\section{MATERIAL E MÉTODOS}

$\mathrm{O}$ ensaio foi executado na área experimental da Embrapa Meio-Norte, Parnaíba, PI (latitude de $3^{\circ} 5^{\prime}$ S, longitude de $41^{\circ} 47^{\prime} \mathrm{W}$ e altitude de 46,8 m) num Neossolo Quartzarênico Órtico Típico (Tabela 1) durante o período de agosto a outubro de 1998. As lâminas de irrigação foram aplicadas através de um sistema de irrigação por aspersão convencional, montado no campo segundo o sistema de "aspersão em linha" (Hanks et al., 1976), com os aspersores espaçados a cada $6 \mathrm{~m}$. Os tratamentos consistiram na combinação de quatro lâminas de irrigação: 449,1; 428,6; 317,1 e 194,4 $\mathrm{mm}$ e duas cultivares de caupi (BR 17 Gurguéia e BR 14 Mulato) dispostos em um delineamento experimental de blocos casualizados, com parcelas subdivididas e cinco repetições. Utilizou-se o espaçamento de $0,80 \mathrm{~m}$ entre as fileiras de plantas, com cinco plantas por metro após desbaste. A parcela experimental tinha uma área de $38,4 \mathrm{~m}^{2}$ $(3,2 \times 12 \mathrm{~m})$ e a subparcela de $19,2 \mathrm{~m}^{2}(3,2 \times 6 \mathrm{~m})$.

Tabela 1. Características químicas e físico-hídricas do solo da área experimental

\begin{tabular}{lcc}
\hline \multicolumn{1}{c}{ Características } & Unidade & Valor \\
\hline $\mathrm{pH}$ em água $(1: 2,5)$ & 6,0 \\
$\mathrm{P}$ & $\mathrm{mg} \mathrm{dm}^{-3}$ & 15,0 \\
$\mathrm{~K}$ & $\mathrm{mg} \mathrm{dm}^{-3}$ & 110,0 \\
$\mathrm{Ca}$ & $\mathrm{mmol}_{\mathrm{c}} \mathrm{dm}^{-3}$ & 30,0 \\
$\mathrm{Mg}$ & $\mathrm{mmol}_{\mathrm{c}} \mathrm{dm}^{-3}$ & 13,0 \\
$\mathrm{Al}$ & $\mathrm{mmol}_{\mathrm{c}} \mathrm{dm}^{-3}$ & 0,0 \\
$\mathrm{Areia}$ & $\mathrm{g} \mathrm{kg}^{-1}$ & 650 \\
$\mathrm{Silte}$ & $\mathrm{g} \mathrm{kg}^{-1}$ & 250 \\
Argila & $\mathrm{g} \mathrm{kg}^{-1}$ & 100 \\
Densidade & $\mathrm{kg} \mathrm{m}^{-3}$ & 1,42 \\
Umidade de saturação $-\theta_{\mathrm{SAT}}$ & $\mathrm{cm}^{3} \mathrm{~cm}^{-3}$ & 0,171 \\
Capacidade de campo $-\theta_{\mathrm{CC}}$ & $\mathrm{cm}^{3} \mathrm{~cm}^{-3}$ & 0,139 \\
Ponto de murchamento permanente $-\theta_{\mathrm{PMP}}$ & $\mathrm{cm}^{3} \mathrm{~cm}^{-3}$ & 0,042 \\
\hline Fonte: Laboratório de Solos - Embrapa Meio-Norte; Os dados referem-se à camada de $0-20 \mathrm{~cm}$
\end{tabular}

O manejo da irrigação baseou-se na utilização do tanque Classe A, adotando-se um turno fixo de irrigação de um dia. As lâminas de irrigação aplicadas foram calculadas com base na evaporação diária do tanque Classe $\mathrm{A}$, utilizando-se coeficientes de tanque (Kp) e de cultura $(\mathrm{Kc})$ definidos em função das condições climatológicas locais (Doorenbos \& Pruitt, 1997; Andrade Júnior et al., 2000), e obtidos experimentalmente para a região, respectivamente. As lâminas de irrigação aplicadas foram medidas por 20 coletores de PVC $(100 \mathrm{~mm})$ distribuídos em quatro linhas paralelas à linha central de aspersores, posicionados no centro da área útil das parcelas selecionadas.

Ao final do ciclo de produção foram avaliados: stand final, comprimento de vagem, massa de 100 grãos, número de vagens por planta, número de grãos por vagem, produtividade de grãos e eficiência do uso de água, a qual foi obtida através da relação entre a produtividade de grãos e as lâminas de irrigação aplicadas. As análises de variância e regressão foram processadas usando-se programa estatístico SAS.

\section{RESULTADOS E DISCUSSÃO}

Os valores referentes às médias de stand final (STF), número de vagens por planta (NVP), número de grãos por vagem (NGV), comprimento de vagem (CV), massa de 100 grãos (MCG), produtividade de grãos (PG) e eficiência do uso de água (EUA) das cultivares de caupi em função das lâminas de irrigação (L) aplicadas são apresentados na Tabela 2.

Tabela 2. Médias* de stand final (STF), número de vagens por planta (NVP), número de grãos por vagem (NGV), comprimento de vagem $(\mathrm{CV})$, massa de 100 grãos (MCG), produtividade de grãos (PG) e eficiência do uso de água (EUA) das cultivares de caupi em função das lâminas de irrigação (L)

\begin{tabular}{|c|c|c|c|c|c|c|c|}
\hline $\begin{array}{c}\mathrm{L} \\
(\mathrm{mm})\end{array}$ & STF & NVP & NGV & $\begin{array}{l}\mathrm{CV} \\
(\mathrm{cm})\end{array}$ & $\begin{array}{c}\text { MCG } \\
(\mathrm{g})\end{array}$ & $\begin{array}{c}\text { PG } \\
\left(\mathrm{kg} \mathrm{ha}^{-1}\right)\end{array}$ & $\begin{array}{c}\text { EUA } \\
\left(\mathrm{kg} \mathrm{m}^{-3}\right)\end{array}$ \\
\hline \multicolumn{8}{|c|}{ BR 17 Gurguéia } \\
\hline 449,1 & 22,0 & 26,0 & 16,2 & 17,4 & 11,7 & 2877,81 & 64,1 \\
\hline 428,6 & 21,8 & 23,7 & 16,0 & 17,4 & 11,8 & 2663,56 & 62,2 \\
\hline 317,1 & 22,0 & 18,5 & 15,6 & 17,4 & 12,8 & 2278,00 & 71,8 \\
\hline 194,4 & 22,0 & 10,5 & 15,0 & 17,5 & 13,8 & 1320,13 & 67,9 \\
\hline Média & $22,0 \mathrm{~A}$ & $19,6 \mathrm{~A}$ & $15,7 \mathrm{~A}$ & $17,4 \mathrm{~B}$ & $12,6 \mathrm{~B}$ & $2284,88 \mathrm{~A}$ & $66,5 \mathrm{~A}$ \\
\hline \multicolumn{8}{|c|}{ BR 14 Mulato } \\
\hline 449,1 & 22,0 & 12,3 & 16,2 & 18,8 & 15,8 & 1853,50 & 41,3 \\
\hline 428,6 & 22,0 & 14,9 & 17,4 & 19,4 & 15,1 & 2211,75 & 51,6 \\
\hline 317,1 & 21,0 & 14,1 & 15,6 & 18,6 & 16,1 & 1900,00 & 60,0 \\
\hline 194,4 & 22,0 & 7,8 & 14,0 & 17,9 & 17,1 & 937,10 & 48,2 \\
\hline Média & $22,0 \mathrm{~A}$ & $12,3 \mathrm{~B}$ & $15,8 \mathrm{~A}$ & $18,7 \mathrm{~A}$ & $16,0 \mathrm{~A}$ & $1725,58 \mathrm{~B}$ & $50,3 \mathrm{~B}$ \\
\hline
\end{tabular}

"Médias seguidas pela mesma letra, na coluna, não diferem estatisticamente pelo teste de Tukey, a níve de $5 \%$ de probabilidade

Os valores das lâminas totais de irrigação aplicadas nas parcelas, foram de 449,1; 428,6;317,1 e 194,4 mm, representando um gradiente de variação decrescente a partir da linha central de aspersores, característica inerente ao sistema de aspersão em linha.

Das variáveis analisadas, o NVP e a PG apresentaram efeito da interação cultivar versus lâminas de irrigação (Figura 1). As variáveis MCG e EUA responderam ao efeito de cultivar e lâmina de irrigação, isoladamente. O NGV variou apenas em função das lâminas de irrigação aplicadas. As diferenças observadas na variável $\mathrm{CV}$ deveram-se unicamente às características agronômicas inerentes à própria cultivar. Em estudo de densidade de plantas versus cultivares de feijão caupi sob irrigação, Cardoso et al. (1997) observaram, também, apenas 
efeito relativo a cultivares para os caracteres $\mathrm{CV}$ e $\mathrm{MCG}$, com a BR 14 Mulato apresentando valores médios de 19,3 cm e 15,8 g, respectivamente.

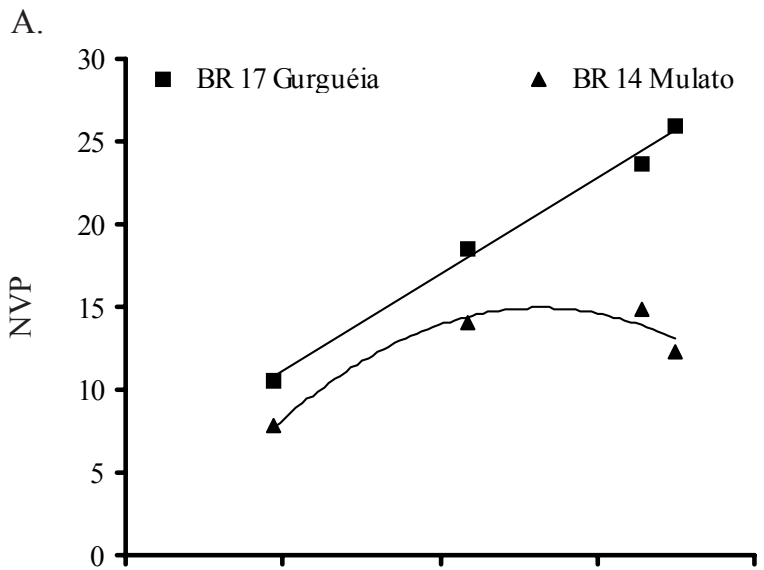

B.

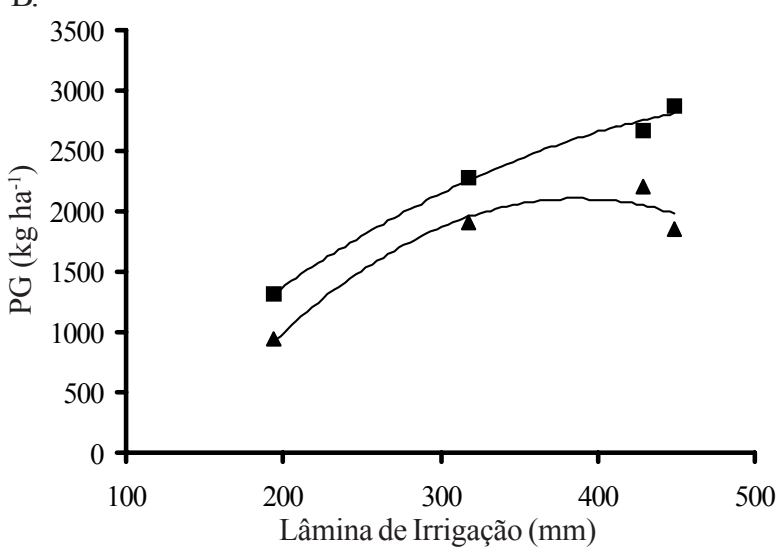

Figura 1. Número de vagens por planta (NVP) (A) e a produtividade de grãos (PG) (B) em função das lâminas de irrigação aplicadas para as duas cultivares de feijão caupi

Observou-se que a cultivar BR 17 Gurguéia apresentou maior PG $\left(2284,9 \mathrm{~kg} \mathrm{ha}^{-1}\right)$ em relação à cultivar BR 14 Mulato $\left(1725,6 \mathrm{~kg} \mathrm{ha}^{-1}\right)$, devido ter apresentado melhor desempenho quanto ao NVP $(19,6)$, apesar do CV $(17,4 \mathrm{~cm})$ e MCG $(12,6 \mathrm{~g})$ terem sido inferiores aos da cultivar BR 14 Mulato $(18,7 \mathrm{~cm}$ e $16,0 \mathrm{~g}$, respectivamente). Este resultado confirma a hipótese de que o componente NVP é o que mais contribui para o aumento da produtividade de grãos em feijão caupi (Cardoso et al., 1995; Cardoso et al., 1997).

A cultivar BR 17 Gurguéia mostrou-se mais eficiente na utilização do fator água para a produção de grãos $\left(66,5 \mathrm{~kg} \mathrm{~m}^{-3}\right)$ que a cultivar BR 14 Mulato $\left(50,3 \mathrm{~kg} \mathrm{~m}^{-3}\right)$. Este comportamento é um reflexo do potencial produtivo diferenciado das cultivares de feijão caupi em resposta à irrigação. Em ensaios irrigados em Parnaíba, PI, conduzidos durante dois anos (1992 e 1993), Cardoso et al. (1995) obtiveram valores médios muito semelhantes para a eficiência de utilização de água com a cultivar BR 14 Mulato $\left(55,0 \mathrm{~kg} \mathrm{~m}^{-3}\right)$.

A análise de regressão para NVP, NGV, PCG, PG e EUA em função das lâminas de irrigação aplicadas, mostrou que essas variáveis apresentaram comportamentos linear e quadrático segundo as equações descritas a seguir (Tabela 3 ).
Tabela 3. Equações de regressão para número de vagens por planta (NVP), número de grãos por vagem (NGV), massa de 100 grãos (MCG), produtividade de grãos (PG) e eficiência do uso de água (EUA) das cultivares de feijão caupi obtidas em função das lâminas de irrigação

\begin{tabular}{llc}
\hline \multicolumn{1}{c}{ Cultivares } & \multicolumn{1}{c}{ Equações de Regressão } & $\mathrm{R}^{2}$ \\
\hline BR 17 Gurguéia & $\mathrm{NVP}=-0,6046+0,0584 \mathrm{~L}$ & 0,99 \\
& $\mathrm{PG}=-942,16+14,203 \mathrm{~L}-0,013 \mathrm{~L}^{2}$ & 0,99 \\
BR 14 Mulato & $\mathrm{NVP}=-18,4278+0,1836 \mathrm{~L}-0,0002526 \mathrm{~L}^{2}$ & 0,94 \\
& $\mathrm{PG}=-2.655,98+24,602 \mathrm{~L}-0,03179 \mathrm{~L}^{2}$ & 0,95 \\
BR 17 Gurguéia & $\mathrm{NGV}=13,068+0,007724 \mathrm{~L}$ & 0,92 \\
BR 14 Mulato & $\mathrm{MCG}=16,896-0,007402 \mathrm{~L}$ & 0,96 \\
& $\mathrm{EUA}=0,595+0,0393 \mathrm{~L}-0,00006412 \mathrm{~L}^{2}$ & 0,99 \\
\hline "L - Lâmina de irrigação, mm; os termos $\mathrm{L}$ e $\mathrm{L}^{2}$ das equações apresentam significância estatistica em
\end{tabular}
nível de $1 \%$ de probabilidade pelo teste $\mathrm{F}$

O maior NVP $(25,6)$ e a máxima PG $\left(2.809 \mathrm{~kg} \mathrm{ha}^{-1}\right)$ para a cultivar BR 17 Gurguéia, foram obtidos com a lâmina de irrigação correspondente a 449,1 mm. Para a cultivar BR 14 Mulato, o NVP $(15,0)$ e a PG $\left(2103,4 \mathrm{~kg} \mathrm{ha}^{-1}\right)$ máximos foram obtidos com as lâminas de irrigação correspondentes a 363,5 e 389,9 mm, respectivamente, constatando-se que o potencial produtivo da BR 17 Gurguéia é superior ao da BR 14 Mulato, mas, face às expectativas de produção devido aos preços de mercado do produto e ao custo da água de irrigação, pode-se indicar perfeitamente o cultivo da BR 14 Mulato em detrimento da BR 17 Gurguéia, uma vez que a primeira possibilita a obtenção de uma boa produtividade de grãos com a aplicação de uma lâmina menor de irrigação. Efeito linear para o NVP e quadrático para a PG em função da aplicação de lâminas de irrigação, também foi observado por Silva (1978) e Frizzone et al. (1987) respectivamente.

Quanto às lâminas para a obtenção da máxima produtividade de grãos, inúmeros trabalhos (Silveira \& Moreira, 1990; Carvalho et al., 1992 e Azevedo \& Miranda, 1996) revelaram que estas variam de 370 a $570 \mathrm{~mm}$ com reflexo direto na produtividade de grãos de 1376 a $2905 \mathrm{~kg} \mathrm{ha}^{-1}$. Constatou-se, portanto, que os valores de lâmina de irrigação e produtividade de grãos obtidos no presente trabalho, estão situados dentro dessa faixa de variação de resultados. As diferenças observadas podem ser devido as cultivares utilizadas e à diversidade das condições edafoclimáticas dos locais onde os estudos foram conduzidos.

Considerando-se a média das duas cultivares, os maiores valores de NGV (16,5), MCG (15,5 g) e aEUA máxima $\left(66,1 \mathrm{~kg} \mathrm{~m}^{-3}\right)$ foram alcançados com a aplicação de 449,1, 194,4 e 306,3 mm, respectivamente (Tabela 2). Apesar das lâminas que maximizam a produção de grãos serem de 449,1 e 389,9 mm para as cultivares BR 17 Gurguéia e BR 14 Mulato, respectivamente, a EUA máxima de 306,3 mm é um indicativo de que a aplicação das lâminas visando à máxima produção de grãos acima desse nível, somente deve ser recomendada economicamente quando a água não for um fator limitante à produção agrícola ou apresentar baixo custo; caso contrário, é aconselhável a definição de um intervalo para o manejo racional da irrigação, a partir das estratégias ótimas econômicas em função do preço do produto e do custo da água, conforme apresentado por Calheiros et al. (1996). 


\section{CONCLUSÕES}

1. As cultivares de feijão caupi testadas responderam diferentemente à aplicação das lâminas de irrigação, no que diz respeito ao número de vagens por planta (NVP) e à produção de grãos (PG).

2. Dos componentes de produção, o NVP foi o que mais influenciou a $\mathrm{PG}$, tendo contribuído para uma performance melhor da cultivar BR 17 Gurguéia.

3. Os componentes número de grãos por vagem (NGV), massa de 100 grãos (MCG) e eficiência de uso de água (EUA) apresentaram efeito isolado quanto à cultivar e lâmina de irrigação.

\section{AGRADECIMENTOS}

Os autores agradecem ao Banco do Nordeste, pelo apoio financeiro indispensável à realização deste projeto de pesquisa.

\section{LITERATURA CITADA}

Andrade Júnior, A.S.; Rodrigues, B.H.N.; Bastos, E.A. Irrigação. In: Cardoso, M.J. (Org.). A cultura do feijão caupi no MeioNorte do Brasil. Teresina: Embrapa Meio-Norte, 2000. p.127-154. Circular Técnica, 28

Azevedo, J.A.; Miranda, L.N. Produtividade do feijão em resposta à adubação fosfatada e regimes de irrigação em solo de Cerrado. II - Manejo da irrigação. In: Reunião Brasileira de Fertilidade do Solo e Nutrição de Plantas, 22, 1996, Manaus. Resumos Expandidos... Manaus: Editora da Universidade do Amazonas, 1996. p.12-13.

Calheiros, C.B.M.; Queiroz, J.E.; Frizzone, J.A.; Pessoa, P.C.S. Estratégias ótimas de irrigação do feijoeiro: água como fator limitante da produção. Pesquisa Agropecuária Brasileira, Brasília, v.31, n.7, p.509-515, 1996.

Cardoso, M.J.; Andrade Júnior, A.S.; Melo, F.B.; Frota, A.B. Avaliação agroeconômica da produção de sementes de caupi sob irrigação. Teresina: EMBRAPA/CPAMN, 1995, 6p. Comunicado Técnico, 62
Cardoso, M.J.; Freire Filho, F.R.; Athayde Sobrinho, C. Cultura do feijão macassar (Vigna unguiculata L. Walp) no Piauí : aspectos técnicos. Teresina: EMBRAPA/UEPAE de Teresina, 1991, 43p. Circular Técnica, 9

Cardoso, M.J.; Melo, F.B.; Andrade Júnior, A.S. Densidade de plantas de caupi em regime irrigado. Pesquisa Agropecuária Brasileira, Brasília, v.32, n.4, p.399-405, 1997.

Carvalho, A.M.; Silva, A.M.; Costa, E.F.; Couto, L. Efeitos de lâminas de água e épocas de parcelamento de nitrogênio em cobertura via fertirrigação no rendimento de grãos do feijoeiro comum (Phaseolus vulgaris L.). In: Congresso Nacional de Irrigação e Drenagem, 9, 1992, Natal. Anais... Fortaleza: ABID, 1992.p.767-789.

Doorenbos, J.; Pruitt, W.O. Necessidades hídricas das culturas. Campina Grande: UFPB, 1997. 204p. Estudos FAO. Irrigação e Drenagem, 24

Felipe, M.P.; Silva, A.M.; Junqueira Neto, A.; Nogueira, F.D. Efeito de diferentes lâminas de água e épocas de adubação nitrogenada sobre a produção de grãos do feijoeiro comum (Phaseolus vulgaris L.). In: Congresso Nacional de Irrigação e Drenagem, 9, 1992, Natal. Anais... Fortaleza: ABID, 1992. p.1249-1271.

Frizzone, J.A.; Olitta, A.F.L.; Pereira, G.T. Funções de resposta do feijoeiro (Phaseolus vulgaris L.) ao uso de nitrogênio e lâmina de irrigação. I - região de produção racional. Item, Brasília, v. 28, p.26-32, 1987.

Hanks, R.J.; Keller, J.; Rasmussen, V.P.; Wilson, G.D. Line source sprinkler for continuous variable irrigation crop production studies. Soil Science Society of America Journal, Madison, v.40, p.426-429, 1976.

Silva, M.A. Efeito da lâmina de água e da adubação nitrogenada sobre a produção de feijão-de-corda (Vigna sinensis L. Savi), utilizando o sistema de irrigação por "aspersão em linha". Viçosa:UFV. 1978. 53p. Dissertação Mestrado

Silveira, P.M.; Moreira, J.A.A. Resposta do feijoeiro a doses de fósforo e lâminas de água de irrigação. Revista Brasileira de Ciência do Solo, Campinas, v.14, p.63-67, 1990. 